\title{
Beam-Column Joints Reinforcement Detailing Adequacy in Case of a Corner Column Loss-Numerical Analysis
}

\author{
B. Abdelwahed ${ }^{a, b^{*}}$ iD \\ a Mansoura University, Mansoura, Egypt. E-mail: bs hadi@mans.edu.eg, bsalahab@vub.ac.be \\ ${ }^{b}$ Vrije Universiteit Brussel, Brussel, Belgium \\ * Corresponding author
}

http://dx.doi.org/10.1590/1679-78255536

\begin{abstract}
This study investigates the behavior of reinforced concrete (RC) beam-column joints at the corner panel after a ground corner column loss scenario. The ductility of a frame is dependent on the ductility of its components, particularly its joints. Deficiency in joints performance can be related to an unexpected event. For example, the removal of a ground corner column turns the joint above into an inverted knee joint, and also inverses the direction of the resulted bending moments in the adjacent exterior and interior joints. Throughout this work, the effects of these changes are evaluated numerically using different modeling techniques considering both seismic and non-seismic reinforcement details. Numerical simulations of standard and sub-standard joints that were verified against experimentally tested joints are also presented. Joint macro models are developed using the OpenSees platform. These numerical models are then used to simulate the substandard beam-column joints appearing in RC frames after ground corner column removal. Moreover, strut and tie models (STMs) were developed for a substandard knee joint to validate the obtained numerical results. The application of the developed numerical models allows to identify the evolution of a joint's capacity in function of its reinforcement detailing. The analysis shows the suitability of seismic detailing for exterior and interior joints and also a decrease in the inverted knee joint resistance and this can be recovered by adding i) more confinement to the joint panel zone or ii) joint vertical stirrups. An increase in the degree of confidence in the numerical results is achieved by reproduce similar behavior using different analysis methods.
\end{abstract}

\section{Keywords}

RC joint, Progressive collapse, Flexural resistance, Numerical simulation, Reinforcement details, Macro model.

\section{INTRODUCTION}

In the analysis or the design of a particular structure, different types of lateral and gravity loads should be considered. RC Code provisions and its proposed reinforcement detailing should be applied to achieve the required resistance for such loads. For that, designers should consider the different load case combinations, even the ones caused by car impact or terroristic attack. The latter may cause damage to one or more of building's ground columns, and therefore designers have to devise a number of systems to cope with such extreme situations. In the event of an unexpected extreme loading, it is essential to guarantee the integrity/stability of the structure during search-and-rescue operations. Hence, the RC frame joints should have an adequate level of ductility and a high load carrying capacity. The loss of a ground corner column turns an exterior beam-column joint into an inverted knee joint as shown in Figure 1 . For any exterior beam-column joint, RC codes (EC2 (2004), ACl 318-08(2008)) prescribe continuous column bars, joint horizontal stirrups and proper beam bar anchorage. While none of them recommend the use of joint vertical stirrups or anchorage of column's bar at exterior joint location. 
Corner column removal event leads to some reinforcement deficiencies in the formed inverted knee joint, such as the absence of joint vertical stirrups and poor anchorage of the column longitudinal bars. These reinforcement defects cause substantial shear deformations in the joint, thus preventing the adjacent beam and column of reaching their flexural capacity as found by Celik and Ellingwood (2008).

In the case of an interior column loss scenario, no local damage is observed in the resulted joint, directly above the removed column (Xiao et al., (2013), Bao et al., (2008)) if the reinforcement detailing of the original joint meets the requirements prescribed by the recent regulation codes. Catenary and Vierendeel actions are the main resisting mechanisms in case of interior column loss. For RC slab and beam elements to better resist the forces from these mechanisms, continuous reinforcement and proper anchorage detailing at joints should be provided along with joints with higher rotation capacity as reported by Gouverneur (2014) and Orton et al. (2009).

On the other side, in case of corner column loss, the required horizontal restraints to form Catenary action do not exist. Therefore, Vierendeel action is the only main resisting mechanism. This mechanism is dependent on the entire frame elements around the lost column and shown by Bao et al. (2008).

Kai and Li (2011) studied the performance of interior beam-column joints, while Yap and Li (2011) studied the performance of exterior beam-column joints after a ground corner column removal. Both of these studies investigated the resistance provided by the beam-column sub-assemblage at location ' $a$ ' and ' $b$ ', as shown in Figure 1, to the damaged structural frames. Kai and Li (2011) reported an increase of $9.7 \%$ in interior joint ultimate capacity by using standard joint reinforcement details. On the other side, Yap and Li (2011) reported an increase of 50\% in exterior joint capacity due to the use of standard details with additional longitudinal bars. Figure 1- $a$ and $b$ show the bending moments changes in a RC frame before and after the loss of the ground corner column respectively. Figure 1-c shows the possible increase in the RC frame deformation. To the authors' knowledge, little is known about the structural behavior of the resulted joints in the panel above the lost corner column.

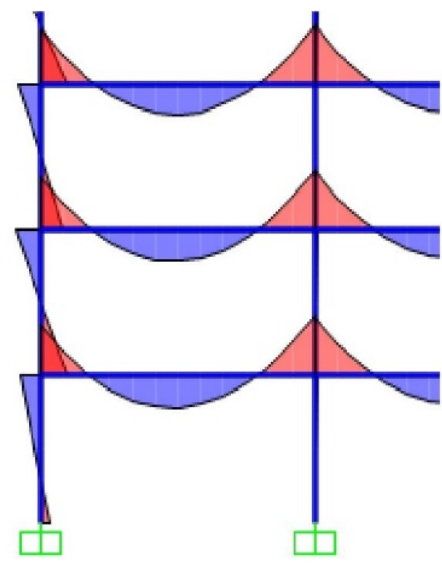

a) Original B.M.D

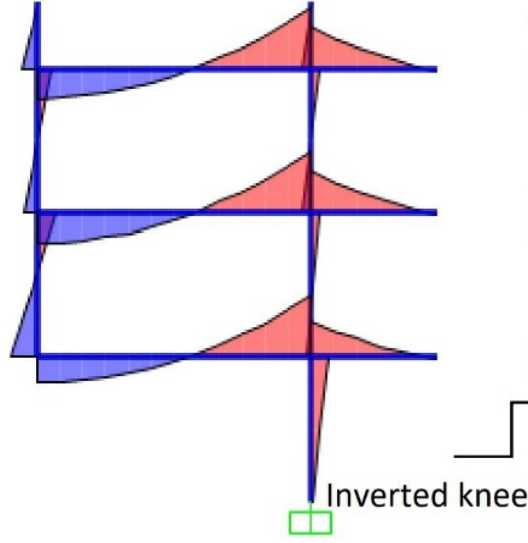

b) B.M.D after column loss

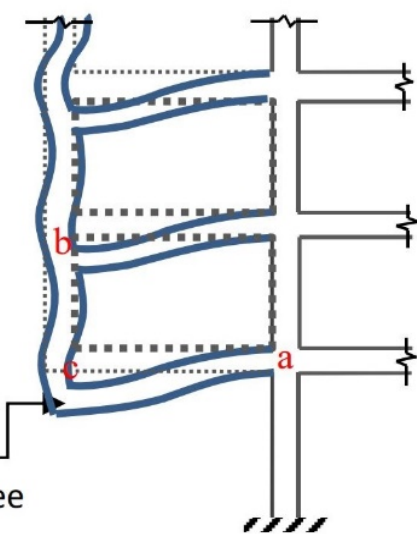

c) Deformed shape

Figure 1: RC frame moment before and after column loss and deformed shape.

As a result, reliable numerical models in different scales are needed for these joints. This paper aims to develop numerical models of the formed inverted knee joint after a corner column loss and for interior and exterior joints as well. These models are then used to assess the performance of the joint considering different reinforcement detailing as presented in Figure 2: (i) standard detailing as recommended by the regulation codes (EC2 (2004), ACl 318-08(2008)), (ii) seismic detailing, with additional vertical stirrups and (iii) detailing prescribed for a knee joint. Software package LS-DYNA, LSTC (2013) was used for similar purpose by Basem et al. (2018) to model in a micro scale the RC knee joints behavior with different anchorage alternatives. They reported that the joint micro model is computationally and time expensive and requires more detailing to model every part in the joint. The results of these micro models are compared to the developed macro numerical model. The latter is built in this study with OpenSees platform (2009), using a macro joint element with a moment-rotation spring and bond-slip zero length elements.

\section{FINITE ELEMENT MACRO MODEL DEVELOPMENT}

A joint macro model from the OpenSees library (2009) is used with modifications to account for the expected shear deformation and the column bar slip. The assessment of the real capacity of the resulted joints (interior, exterior and inverted knee) in the panel above the lost ground corner column is essential to evaluate the whole RC structure resistance 
as shown in Figure 2. The reliability of the numerical results is dependent on the capability of simulating the brittle failure modes at ultimate states. This aspect requires numerical models as the models proposed for these joints as presented in Figure 3.

a) RC frame

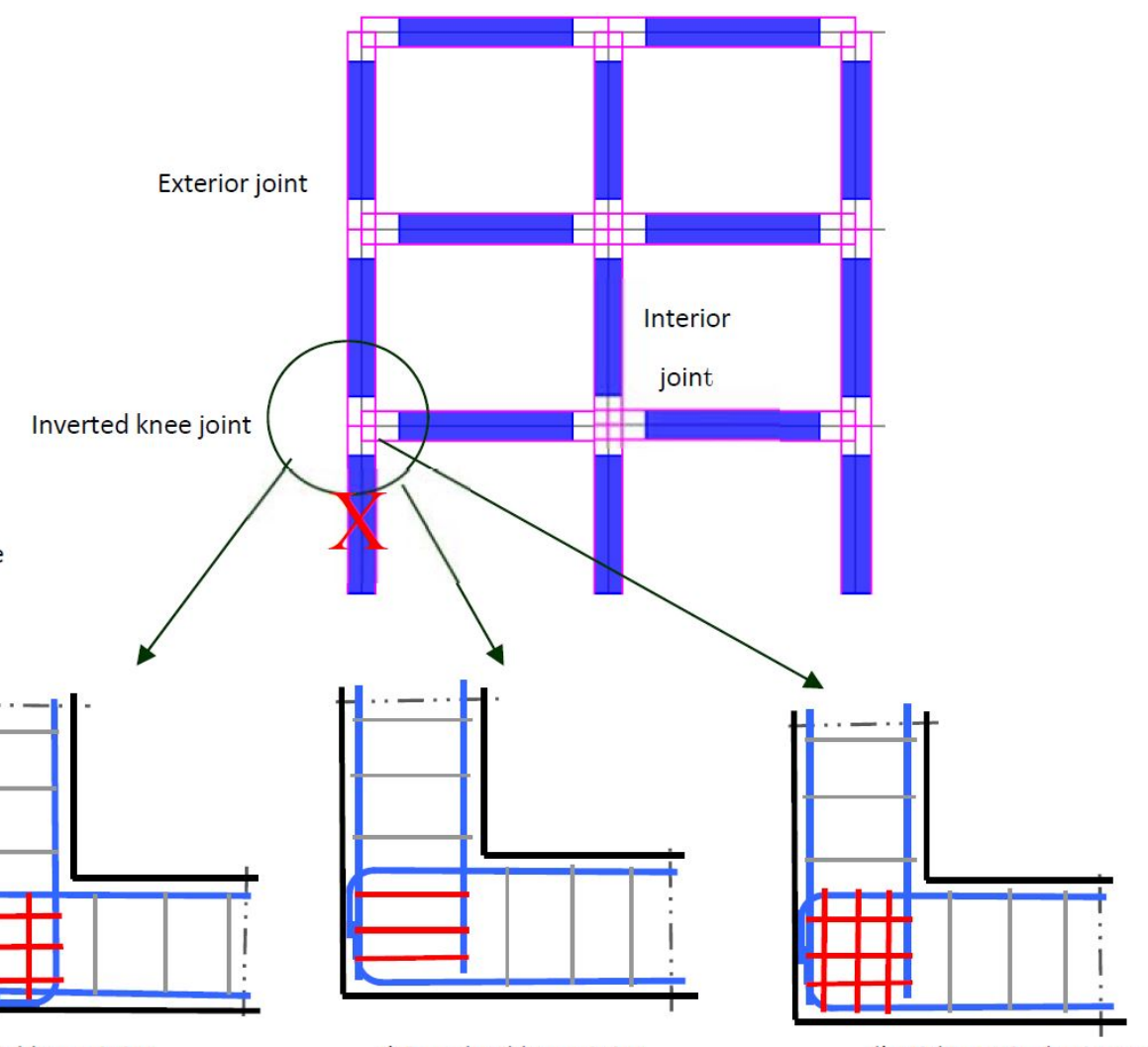

b) Standard knee joint

c) Resulted knee joint

d) with vertical stirrups

Figure 2: Different joint details in RC frame after a left corner column removal.
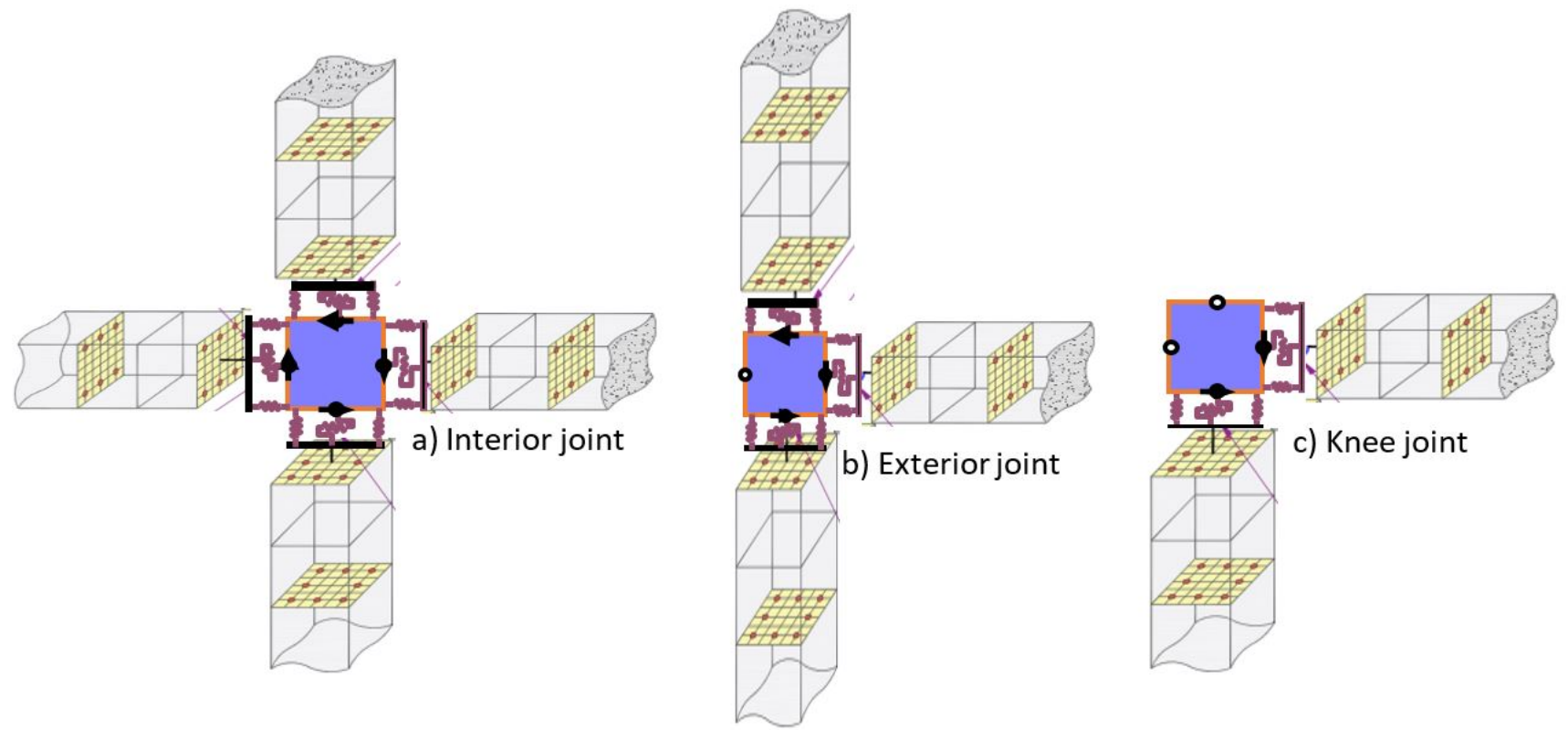

Figure 3: Different Beam-Column joints numerical macro models.

The open source platform OpenSees (2009) offers a framework for incorporating discrete nonlinear springs that allow the simplification of the complex nonlinear response of the joint. Nonlinear stress-strain relationship of concrete is considered using the Concrete02 material model available in OpenSees (see Figure 4-a). This model accounts for the spacing 
and yield strength of the transverse reinforcement on the strength and the ductility of the concrete. For the reinforcing steel rebars, the Steel02 model with a bilinear monotonic stress-strain relationship is adopted, (see Figure 4-b).

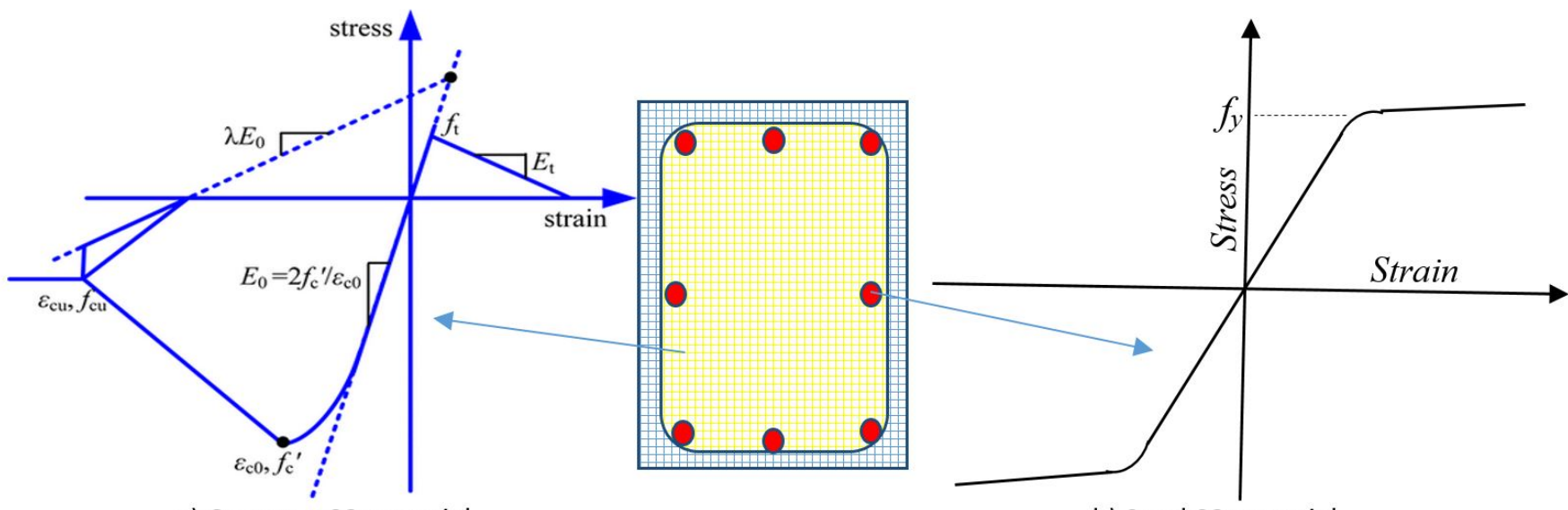

a) Concrete 02 material

b) Steel 02 material

Figure 4: Concrete and steel stress-strain relationship from Opensees (2009).

A nonlinearBeamColumn element, based on the iterative force formulation which considers the spread of plasticity along the element was adopted. In this study, five integration points were chosen for the column and the beam elements. In order to evaluate the effect of the joint flexibility and the propagation of joint failure on the response of the whole structure, many implicit and explicit joint macro models with simple rotation springs or more detailed spring assemblies have been proposed to reproduce the joint behavior. The joint element used in this study is based on the model proposed by Lowes et al. (2003). This element simulates the response of RC beam-column joints (see Figure 5-a).

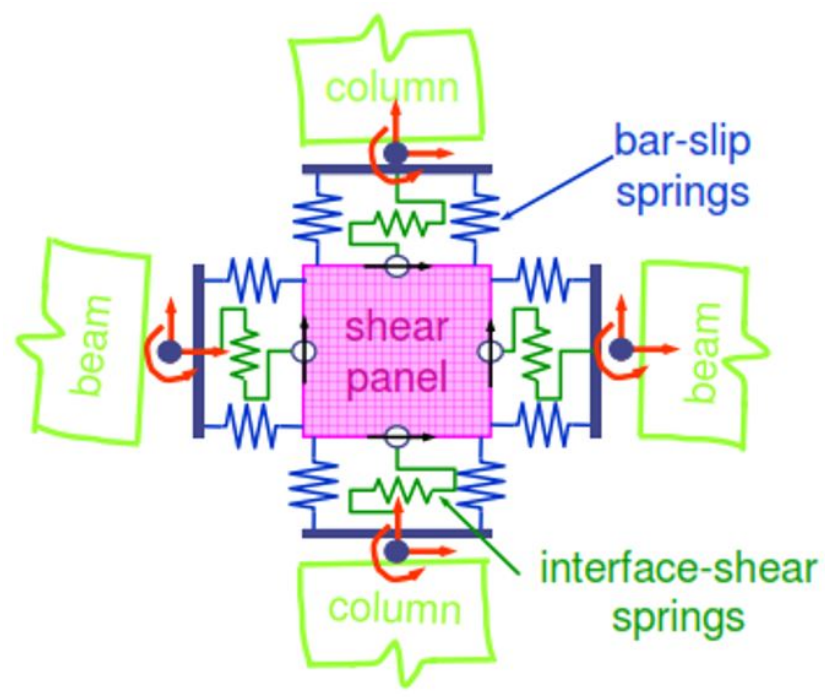

a) beam-column joint model Components

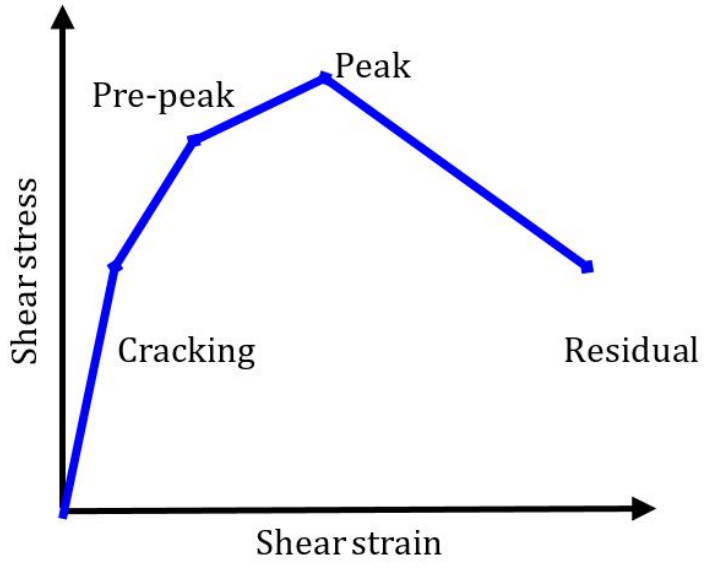

b) Joint shear panel key points

Figure 5: Beam-column joint element proposed by Lowes et al. (2003).

This BeamColumnJoint element consists of one shear panel element, eight bar-slip springs and four interface-shear springs. Shear panel elements are used to simulate strength and stiffness degradation due to failure of the joint panel. Joints are defined by four nodes where one dimensional beam and column elements intersect. To account for joint shear panel deformation, a characteristic for joint rotational spring is proposed. In this study, a backbone curve is proposed based on the joint responses measured from different joint specimens discussed in the literature (Celik and Ellingwood (2008), Park and Mosalam (2013), Teraoka and Fujii (2000), Jalil et al. (2014) and Maria (2015)). This piecewise linear curve, depicted in Figure $5-b$, gives the relation between the shear stress and strain and is described by four key points, which correspond to (i) the joint shear cracking strength, (ii) the yielding of the reinforcement, (iii) the joint shear strength and (iv) the residual strength. Their 
values are found to be in the range of: (i) $\left[0.4,0.56 \sqrt{f_{c}}\right]$, (ii) $\left[0.6,0.93 \sqrt{f_{c}}\right]$, (iii) $\left[0.62,1.1 \sqrt{f_{c}}\right]$ and (iv) $\left[0.35,0.5 \sqrt{f_{c}}\right]$ (in MPa) respectively. The corresponding strain ranges for the four key points are: (i) [0.01\%, $0.13 \%]$, (ii) [0.2\%, $1 \%]$, (iii) [1\%, $3 \%]$ and (iv) $[2 \%, 4 \%]$ respectively.

The bar-slip springs simulate the stiffness and the strength degradation due to damage in the anchorage zone and are defined using the uniaxial Material Bar Slip model. This model gives the possibility to define the bar embedded length, the anchored bar material characteristics and the bond condition. The spring capacities are determined based on the ultimate strain of the concrete, i.e. 0.003. The reinforcing bars and the concrete in compression determine the compression spring capacity, while the contribution of concrete is ignored for the tension spring. The capacity of the tension springs is the controlled by bond pull out resistance at the joint, which is function of the reinforcing bars development length, number and location of the anchored bars and real bond strength. The yield strength of the tension spring is the smallest value of the computed capacity due to flexural or bond pull out failure. For instance, in the case of the resulted knee joint after a column loss, the column bars anchorage length is not sufficient to reach the yield limit, thus the bond pull out failure is the predominant failure mode. If the column bars are well anchored, the flexural ductile failure is the predominant failure mode. The solver calculates the spring force and the secant stiffness from the input spring deformation.

\section{BEAM-COLUMN JOINTS}

Two interior beam-column joints examined by Kai and Li (2011) and two exterior tested by Yap and Li (2011) are selected to be simulated numerically with OpenSees to validate the developed numerical models. The selected joints represent two types of failure mechanisms: joint-shear failure and beam-flexural failure as consequence of using substandard and standard reinforcement detailing respectively. A view of the beam-column joints detailing, and dimensions are shown in Figures 6 and 7. For substandard specimens, joint core is lack of transverse stirrups and column bars are spliced above the joint in contrary to situation in standard detailed joints.

These beam-column joints, referred to as substandard (with old detailing) and standard (with seismic detailing), were designed and examined to study the added amount of resistance with varying the amount of joint transverse reinforcement.

For the exterior joints, the concrete compressive strength was $30 \mathrm{MPa}$ and as the transverse reinforcement yield strength and its spacing affect the strength and ductility of confined concrete, in these simulations two concrete models are used; one for beams and columns elements in confined joint model and latter in unconfined one as presented in Table 1. The reinforcing steel yield strength, ultimate strength and yield strain were: $559.0 \mathrm{MPa}, 606.6 \mathrm{MPa}$ and $2.545 \mathrm{e}-3$ respectively.

Table 1: Values adopted for the material model parameters used in OpenSees models.

\begin{tabular}{ccccc}
\hline Concrete02 & fpc (MPa) & $\varepsilon c$ & fpcu (MPa) & $\varepsilon c u$ \\
\hline Confined & 30.8 & 0.003 & 6.0 & 0.005 \\
Unconfined & 30 & 0.002 & 3.0 & 0.0035 \\
\hline
\end{tabular}

For the interior joints simulation, just the concrete compressive strength and steel yield strength are changed to be $29.5 \mathrm{MPa}$ and 505.6 MPa respectively according to Kai and Li (2011).

In this study the shear stress-strain values used in defining the backbone curve of the panel zone for the considered joints are presented in Table 2.

Table 2: Proposed shear stress-strain values for different joints.

\begin{tabular}{|c|c|c|c|c|c|c|c|c|}
\hline \multirow{3}{*}{ Damage condition } & \multicolumn{4}{|c|}{ Kai and Li joints } & \multicolumn{4}{|c|}{ Yap and Li joints } \\
\hline & \multicolumn{2}{|c|}{ Substandard } & \multicolumn{2}{|c|}{ Standard } & \multicolumn{2}{|c|}{ Substandard } & \multicolumn{2}{|c|}{ Standard } \\
\hline & Stress (MPa) & Strain & Stress (MPa) & Strain & Stress (MPa) & Strain & Stress (MPa) & Strain \\
\hline Cracking & 1.7 & 0.002 & 2.2 & 0.002 & 1.3 & 0.002 & 2.1 & 0.002 \\
\hline Pre-peak & 3.1 & 0.004 & 4.1 & 0.004 & 2.3 & 0.004 & 4.0 & 0.004 \\
\hline Ultimate & 3.35 & 0.013 & 4.5 & 0.02 & 2.8 & 0.009 & 4.2 & 0.013 \\
\hline Residual & 1.0 & 0.022 & 1.5 & 0.04 & 0.8 & 0.018 & 1.2 & 0.037 \\
\hline
\end{tabular}






Figure 6: Layouts and details of Kai and Li (2011) interior beam-column joints. 

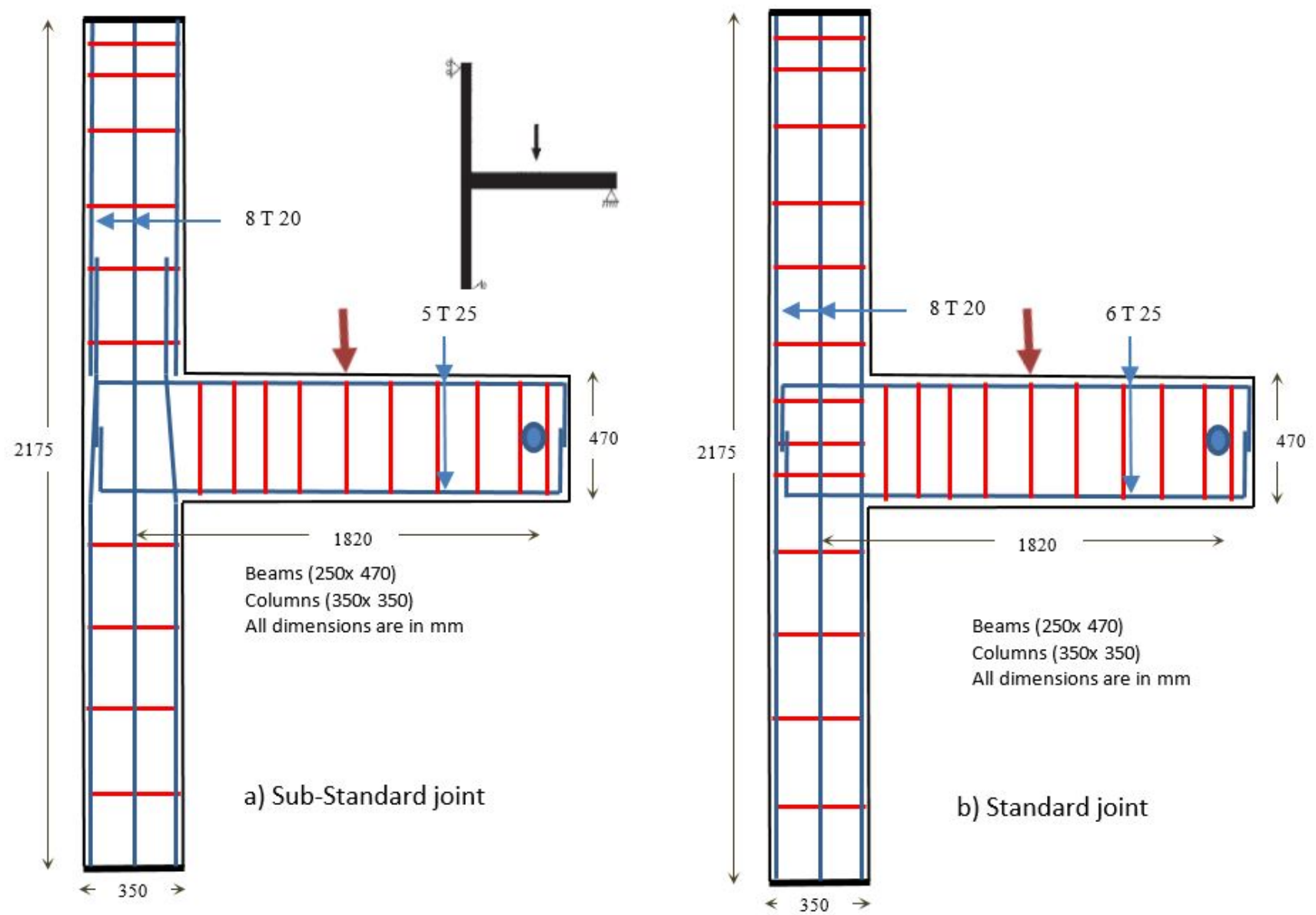

Figure 7: Layouts and details of Yap and Li (2011) exterior beam-column joints.

\section{RESULTS AND DISCUSSION}

Figure 8 shows the numerical and experimental force-displacement response of the two interior RC joints. The horizontal axis represents the vertical displacement at the loading point, while the vertical axis represents the joint resisting force capacity. As can be depicted from Figure 8, the numerically predicted force-displacement responses were in a good agreement with the experimentally recoded ones. The force-displacement response can be characterized by only two phases. During the first phase, high primary stiffness can be observed until the steel reinforcement reaches the yielding point. The corresponding displacement for the yielding point was 17 and $22 \mathrm{~mm}$ for the substandard and standard joints, respectively, as shown in Figure 8. In the second phase, the displacement increases in higher rate until failure occurs. The absence of any descending branches can be attributed to the nature of loading in these tests, in which the applied loading caused flexure action without normal forces on the loaded specimens.

For the substandard joint, the numerical flexural peak force is $192 \mathrm{kN}$, which is $98 \%$ of the corresponding experimental value of $196 \mathrm{kN}$. The corresponding vertical displacements, at which these peak forces occur, are $76 \mathrm{~mm}$ for the numerical model compared to $100 \mathrm{~mm}$ for the experimental case. The numerical flexural peak force is well predicted while the displacement capacity is underestimated. This may be attributed to the limited rotational capacity for both beam and joint panel zones which causes divergence problems at the advanced stage of loading and limits the numerical model to reach the observed experimental displacement capacity.

For the standard joint, the numerical flexural peak force is $206 \mathrm{kN}$, which is $95 \%$ of the corresponding experimental value of $215 \mathrm{kN}$. The corresponding vertical displacements at which these peak forces occur are $145 \mathrm{~mm}$ for the numerical model and $150 \mathrm{~mm}$ for the experimental test. In this particular case, the numerical model divergence problem has disappeared as the joint panel zone has a high rotation capacity which allows the model to reach high displacement levels and predict reasonable values compared to the experimental values. 
In Figure 9 regarding exterior joints, the experimental and numerical force-displacement responses show similar patterns: first ascending branch followed by a drop in the rate of the increase in resisting force, this drop of the resisting force is at approximately $12 \mathrm{~mm}$ of displacement due to bar yielding for both substandard and standard joints, and second ascending branch is due to main reinforcement hardening till reaching ultimate capacity. The descending branches were attributed to the nature of loading in this test in which the applied loading caused both flexure and normal effects in the loaded beam. For substandard joint, the numerical flexural peak force is $200 \mathrm{kN}$, which is $104 \%$ of the corresponding experimental value of $191.1 \mathrm{kN}$. The corresponding vertical displacements at which these peak forces occur are $40 \mathrm{~mm}$ for both the numerical model and the experimental case. For standard joint, the numerical flexural peak force is $300.7 \mathrm{kN}$, which is closer to the corresponding experimental value of $299 \mathrm{kN}$. The corresponding vertical displacements at which these peak forces occur are $74 \mathrm{~mm}$ for the analytical model compared and $80 \mathrm{~mm}$ for the experimental case.

The differences between standard and substandard joints ultimate capacities are attributed to the increase in the beam longitudinal reinforcement ratio and the presence of joint transverse reinforcements which resulted in a higher beam bending moment capacity and improved joint rotational capacity.

Based on the comparison of the numerical and experimental results, the joint macro modeling with the proposed backbone curve can accurately predicts the load-displacement responses of the interior and exterior RC joints in these particular loading conditions. While some discrepancies after the peak loads are found. This may be attributed to the absence of post peak degradation as a result of applied monotonic loading type. This degradation can only be occurred due to damage in bar bond slip spring under cyclic loading as previously reported by Celik and Ellingwood (2008).
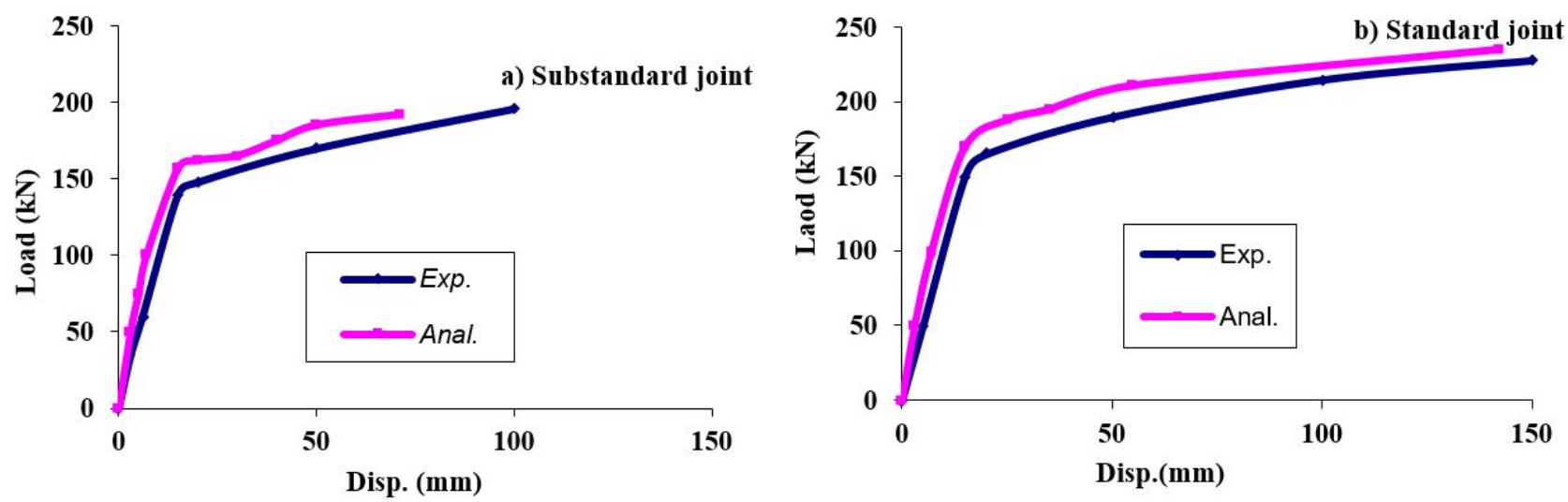

Figure 8: Comparisons of the interior joint load-displacement responses for specimens tested by Kai and Li (2011).
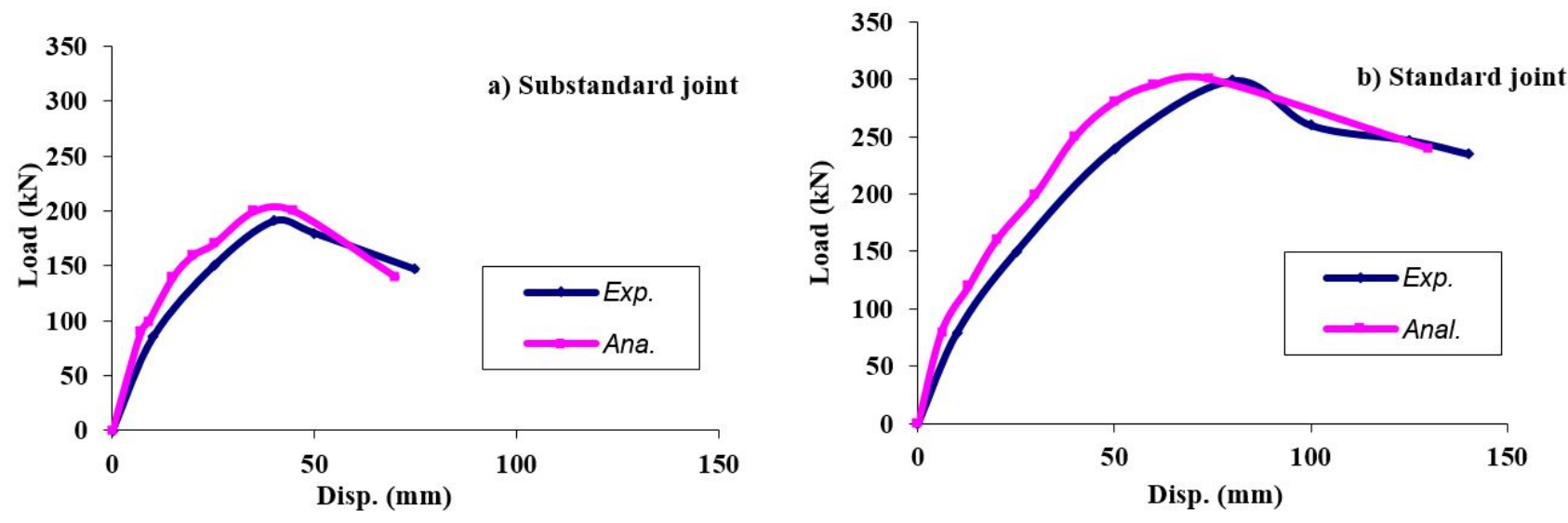

Figure 9: Comparisons of the exterior joint load-displacement responses for specimens tested by Yap and Li (2011).

\section{KNEE JOINT CASE STUDY}

In the previous sections, the validity of the proposed backbone curve for the joint panel zone is shown for both exterior and interior joints. The validation process is done as a result of availability of experimental tests of both standard and substandard exterior and interior joint. For the considered knee joint case study from Wallace et al. (1998), there are no 
available experimental tests evaluating joints without both vertical stirrups and improper column anchorage. For that, numerical modeling results from OpenSees numerical simulations and analytical results from STMs are compared to the available numerical results in Basem et al. (2018). A schematic representation for each method is shown in Figure 10.

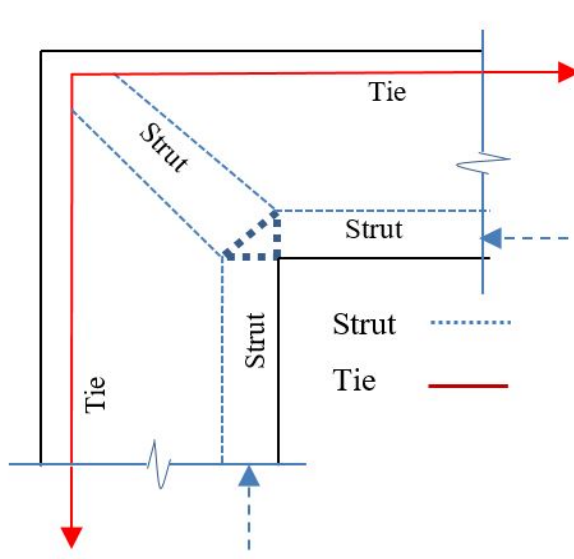

a) STM

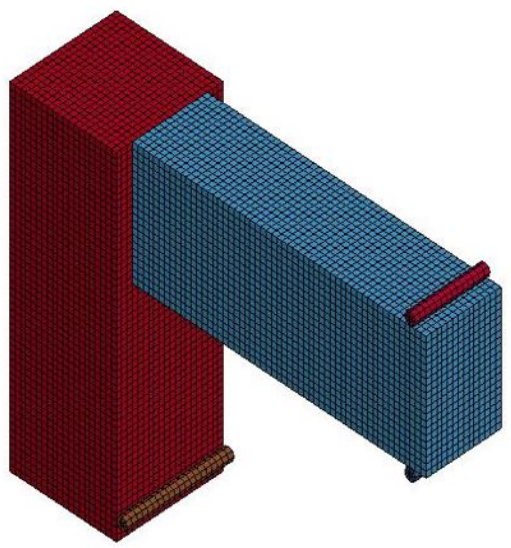

b) Micro model

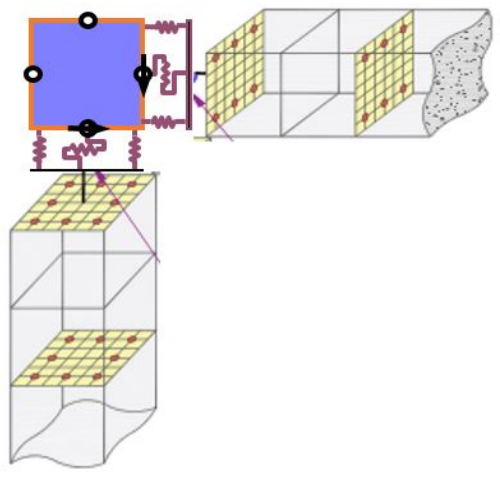

c) Macro model

Figure 10: Comparative analyses, using STM, micro and macro modeling for the knee joint.

\subsection{Standard Knee Joint}

A knee beam-column joint examined by Wallace et al. (1998) is selected to be simulated numerically with OpenSees. The selected joint represent standard type of reinforcement, in which all beam and column longitudinal reinforcement are anchored properly in the joint with $90^{\circ}$ standard hook, also the joint panel contains both vertical and horizontal stirrups. The failure mechanisms expected was beam-flexural failure.

As shown in Figure 11, the experimental and numerical force-displacement responses show similar patterns to some extent. For this joint, the numerical flexural peak force is $272 \mathrm{kN}$, which is $103 \%$ of the corresponding experimental value of $264 \mathrm{kN}$. The corresponding vertical displacements at which these peak forces occur are 22 and $25 \mathrm{~mm}$ for the numerical model and the experimental case, respectively. The OpenSees macro model results were also in a good agreement with the micro modeling results with LS-DYNA which gives joint ultimate load carrying capacity of $275.3 \mathrm{kN}$ at $19 \mathrm{~mm}$ displacement, more details about LS-DYNA model and results are available in Basem et al. (2018).

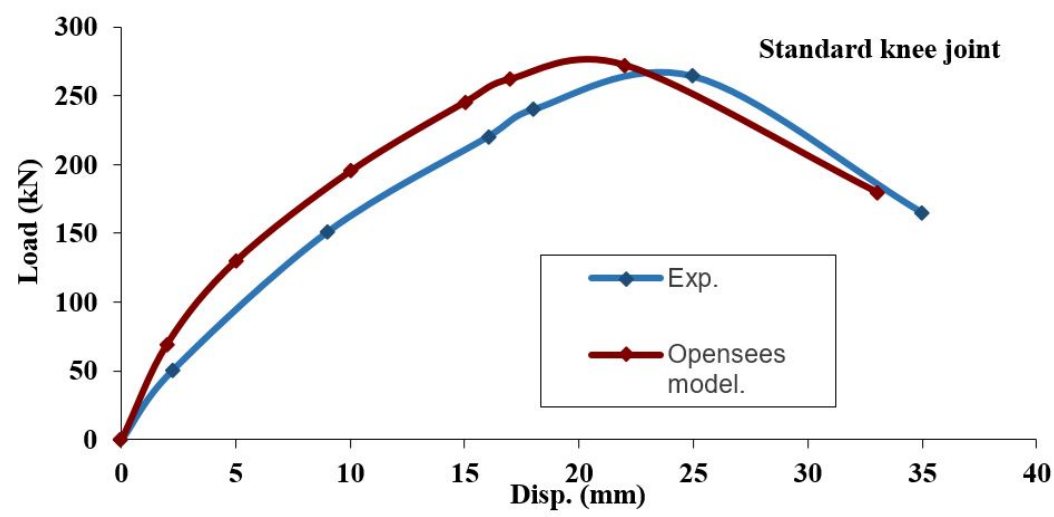

Figure 11: Comparisons of the joint numerical load-displacement responses with the experimental responses.

\subsection{Substandard Knee Joint}

In the context of progressive collapse, after event of corner column failure, some sources of reinforcement defects take place; absence of joint vertical stirrups and improper column bar anchorage like what previously presented in Figure 2-c. In this part, the attention is focused on joints with different reinforcement defect conditions and the corresponding shear strength of the joint panel zone. For these substandard cases, joint core is missing vertical transverse stirrups and proper column bars anchorage in contrary to the situation of standard detailed joints. 
For standard knee joint simulated in the previous part, the peak shear stress value that can be resisted by the joint panel zone was taken as $2.8 \mathrm{MPa}$ and this stress value is formed as a contribution of joint concrete strength and joint transverse reinforcement. Any defects in the joint reinforcement details negatively affect joint shear strength, a reduction because of improper bar anchorage or due to combined effects of both anchorage and shear reinforcement inconvenience are shown in Table 3 using different equations. Two new models simulating the resulted knee joint are made; one for joint with just anchorage defects and other for joint with both anchorage and shear reinforcement defects and the specified joint peak shear stresses are 2.6 and $2.2 \mathrm{MPa}$ respectively.

Table 3: Percentage of reduction in joint shear strength according to reinforcement defects.

\begin{tabular}{ccc}
\hline Used equ. & Anchorage defects \% & Anchorage \& shear defects \% \\
\hline Hegger et al. (2003) & 5.4 & 19 \\
Wang et al. (2012) & 4.45 & 20.5 \\
\hline
\end{tabular}

In Figure 12, the numerical force-displacement responses for standard, anchorage deficient models and model with both anchorage and shear deficiency show general similar patterns. For the anchorage deficient joint, the numerical flexural peak force is $246.3 \mathrm{kN}$, which is $90.6 \%$ of the corresponding standard numerical value of $272 \mathrm{kN}$. The corresponding vertical displacements at which these peak forces occur is $16 \mathrm{~mm}$ for anchorage deficient model and $22 \mathrm{~mm}$ for standard case. For joint model with both anchorage and shear reinforcement defects, the numerical flexural peak force is $208.13 \mathrm{kN}$, which is $76.5 \%$ of the corresponding standard numerical value. Also, the corresponding vertical displacements at which this peak force occur is $16 \mathrm{~mm}$. For the model with just anchorage deficiency, the existence of joint vertical stirrups improves the joint capacity by about $18.3 \%$ compared to the model without stirrups and increases joint ultimate displacement capacity from 22 to $28 \mathrm{~mm}$.

The OpenSees macro model findings are in a good agreement with the micro modeling results with LS-DYNA which gives joint ultimate load carrying capacity of these substandard cases 93 and $73 \%$ of the corresponding standard numerical value.

From Figure 12, the post peak response of the joint is controlled by the longitudinal reinforcing steel and the confinement provided by the transverse reinforcement. While adequately confined concrete exhibits more ductile behavior then the poorly confined (unconfined) joints which degraded rapidly.

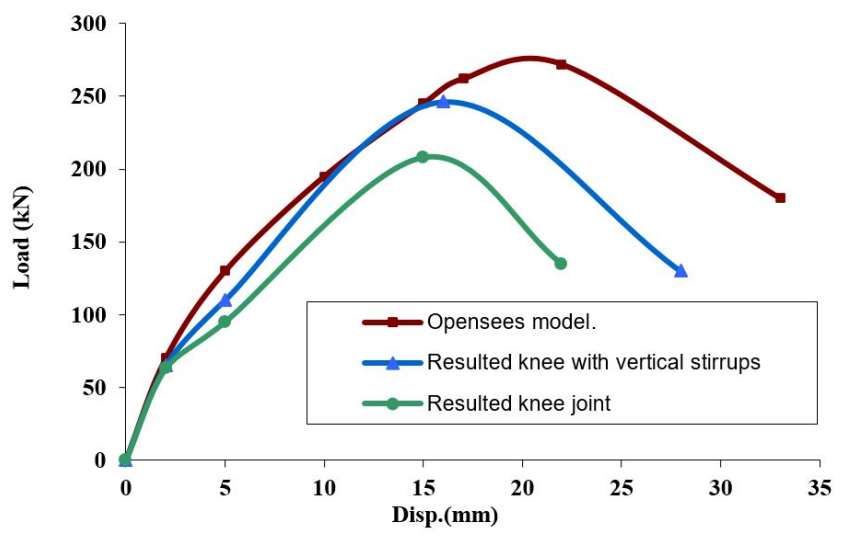

Figure 12: Comparisons of the joint analytical load-displacement responses with different level of joint reinforcement defects.

After validation of the numerical macro models results compared to available results in literature, STM is used. Generally by developing a simplified STM like the one shown in Figure 10-a, column outer bar force is controlled by concrete bond strength characteristics. The peak value of concrete bond strength is calculated based on equation from Comite Euro-International du Beton - Federation Internationale de la Precontrainte, 2010 which leads to a tension force of $136 \mathrm{kN}$ in each column bar ( 3 bars are in tension side) which is less than $146.6 \mathrm{kN}$ maximum bar yield capacity force. In which the calculated joint ultimate carrying capacity is reduced by $7.2 \%$ as a direct consequence of this defect in column bars anchorage.

For developing more refined STM, Brown et al. (2006) concluded that, reinforcement should fit to the assumed STM geometry and satisfy anchorage requirements and if not, one has to change the ties or nodes location and modify STM. The refined STMs have been developed to model the flow of forces through the knee joint under a closing moment 
action, one with perpendicular joint ties and other with inclined ones to match closely with the elastic stress trajectories in case of improper column bar anchorage. For the STM with inclined ties in Figure 13-b, a reduction of $8.5 \%$ in column outer bars forces as a result of lowering the position of intersection node between ties T3 and T5 is recorded. In conclusion, STM findings are found in a good agreement compared to the corresponding macro and micro numerical findings as shown in Figure 14.

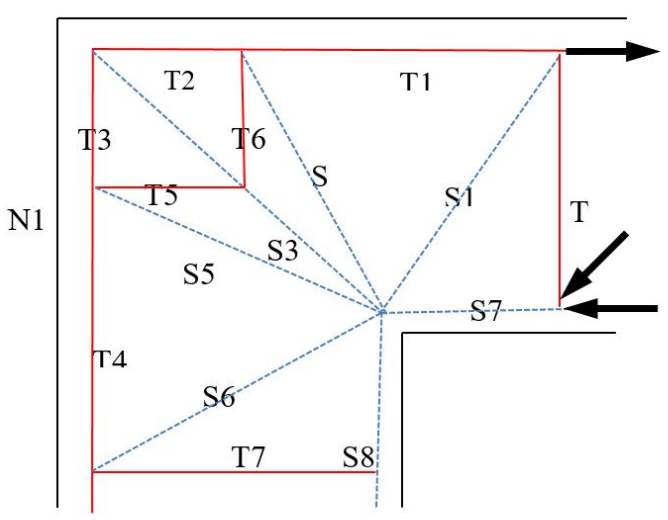

a) STM with perpendicular ties

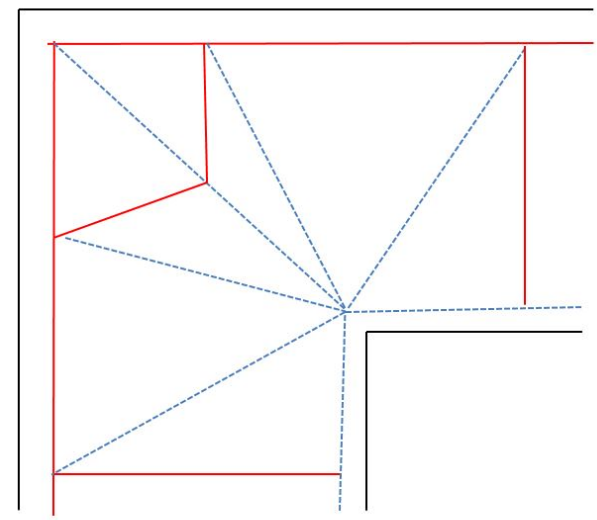

b) STM with inclined ties

Figure 13: Components of the proposed STM for a knee joint under a closing moment.

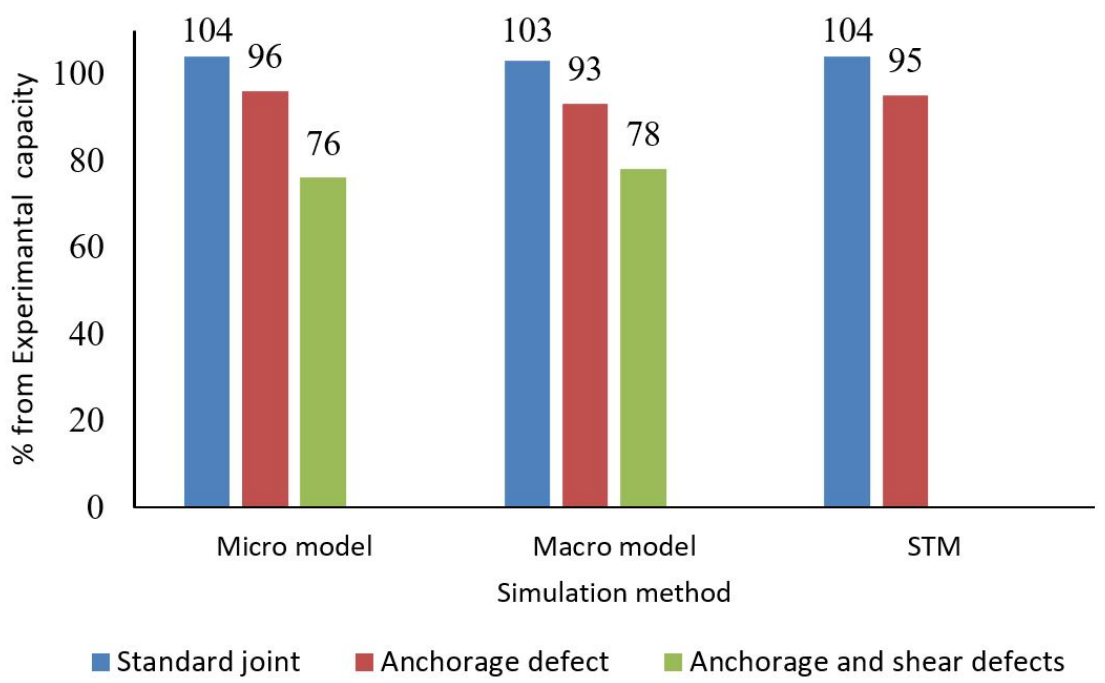

Figure 14: RC Knee joint ultimate capacity by different analyses under a closing moment.

\section{CONCLUSIONS}

This study developed reduced-order models with beam, joint panel and spring elements to represent the nonlinear behavior of different RC joints. These models can be used as an effective tool to evaluate the ability of RC frames to resist progressive collapse after a corner column removal. The conclusions from the analysis of different numerical models are presented as follows:

1. The application of the developed models allow identifying the evolution of joints capacity in function of reinforcement detailing according to the standard prescriptions of regulation codes for different joints.

2. Macro models for both exterior and interior joints get around the detailing of the joint and are able to predict their response with a reasonable computation time and acceptable accuracy.

3. An improper columns bar anchorage affects the joint flow of forces and causes an increase in joint transverse reinforcement forces and a reduction in joint ultimate capacity is observed if no joint transverse reinforcement is provided. 
4. The developed numerical models can reasonably predict the response of the substandard beam-column knee joints, if a proper constitutive shear stress-strain relationship is defined for the joint shear panel zone.

5. Modeling different reinforcement defects as a joint shear strength reduction in this study; accepted predictions are achieved for beam-column joints failed in brittle or ductile manners.

6. Seismic reinforcement detailing is found relevant for both interior and exterior joints and this detailing for the resulted knee joint is found not enough and additional vertical stirrups are highly needed.

The current study highlighted the effects of reinforcement detailing of different RC joints (Interior, Exterior and Knee) on their performance after a corner column loss. Further work is needed with OpenSees code to better reproduce joint post peak behavior and achieve compatibility requirements when implemented in the whole frame model.

\section{Acknowledgments}

The author would like to thank Dr. Mohamed Elghazy in Laval University for constructive discussion and suggestions about the manuscript. Also thanks to Dr. Mohamed Sayed in Toronto University for valuable feedback about numerical models with OpenSees.

Editor: Marco L. Bittencourt.

\section{References}

ACI 318-08 Committee, (2008). Building Code Requirements for Structural Concrete and Commentary, American Concrete Institute, Farmington Hills, Michigan.

Bao, Y., Sashi, K., Sherif, El., Lew, H., (2008).Macro model-based simulation of progressive collapse: RC frame structures. Journal of Structural Engineering 2008; Vol : 134 Issue 7. https://doi.org/10.1061/(ASCE)ST.1943-541X.0000773.

Basem, A., Bachier, B., and John, V., (2018). Reinforced Concrete Beam-Column Inverted Knee Joint Behavior after Ground Corner Column Loss-Numerical Analysis. Latin American Journal of Solids and Structure. Vol 15 No 10 (2018).

Brown, M. D., Sankovich, C. L., Bayrak, O., Jirsa, J. O., Breen, J. E., and Wood, S. L. (2006). Examination of the AASHTO LRFD Strut and Tie Specifications. Center for Transportation Research Report 0-4371-2, University of Texas, Austin, 330 pp, 2006.

Celik, O., Ellingwood, B. (2008). Modeling beam column joints in fragility assessment of gravity load designed reinforced concrete frames. Journal of Earthquake Engineering. 2008; Mar 14;12 (3):357-381. https://doi.org/10.1080/13632460701457215.

Comite Euro-International du Beton - Federation Internationale de la Precontrainte, CEB FIP Model Code, 2010.

European Committee for Standardization: EN 1992-1-1 (2004): Eurocode 2: Design of concrete structures - Part 1-1: General rules and rules for buildings.

Gouverneur, D. (2014). Experimental and Numerical Analysis of Tensile Membrane Action in Reinforced Concrete Slabs in the Framework of Structural Robustness, Ph.D. Thesis, Ghent University, Belgium.

Hegger, J., Roeser, W., Sherif, A. (2003). Nonseismic Design of Beam-Column Joints. ACI Structural Journal 100(5):654-664.

Jalil, S., Mohammad, S., Abdollah, H., Mohammd, S., (2014). Effects of joint flexibility on lateral response of reinforced concrete frames. Engineering Structures 2014; 81: 412-431. https://doi.org/10.1016/j.engstruct.2014.09.046.

Kai, Q., Li, B., (2011). Experimental and analytical assessment on RC interior beam-column subassemblages for progressive collapse. J. Perform. Constr. Facil., 2011; 26(5), 576-589. https://doi.org/10.1061/(ASCE)CF.1943-5509.0000284.

Livermore Software Technology Corporation, LSTC. (2013). Keyword User's Manual: Material Models. Livermore Carlifornia, USA.

Lowes, L., Mitra, N., Altoontash, A. (2003). A beam-column joint model for simulating the earthquake response of reinforced concrete frames. PEER-2003/10.

Maria, T., (2015) Ph.D Thesis. Seismic performance assessment of RC buildings accounting for structural and non-structural Elements. University of Naples Federico II (2015). 
OpenSees (2009). Open System for Earthquake Engineering Simulation. Pacific Earthquake Engineering Research Center, University of California, Berkeley. http://opensees.berkeley.edu.

Orton, S., Jirsa, J. O., and Bayrak, O. (2009). Carbon fiber-reinforced polymer for continuity in existing reinforced concrete buildings vulnerable to collapse. ACI Struct. J., 106(5), 608-616.

Park, S., Mosalam, K., (2013). Simulation of reinforced concrete frames with nonductile beam-column joints. Earthquake Spectra, 2013b; 29(1), 233-257. https://doi.org/10.1193/1.4000100.

Teraoka, M., Fujii, S., (2000). Seismic damage and performance evaluation of R/C beam column joints. In The Second US-Japan Workshop on Performance-Based Engineering for Reinforced Concrete Building Structures (2000) (pp. 379-390). https://peer.berkeley.edu/publications/peer_reports/reports_2000/0010.pdf.

Wallace, J.W., McConnell, S.W., Gupta, P., Cote, P.A. (1998). Use of Headed reinforcement in Beam-Column Joints Subjected to Earthquake Loads. ACI Structural Journal, Vol. 95, No. 5:590-606.

Wang, G., Dai, J., Teng, J., (2012). Shear strength model for RC beam-column joints under seismic loading. Engineering Structures 2012; vol. 40: pp. 350-360. https://doi.org/10.1016/j.engstruct.2012.02.038.

Xiao, Y., Zhao, Y., Li, F., Kunnath, S., Lew, H. (2013). Collapse test of a 3-story half-scale RC frame structure. Structures Congress 2013; pp. 11-19, Pittsburgh, PA, USA. https://doi.org/10.1061/9780784412848.002.

Yap, S.L., Li, B. (2011). Experimental Investigation of RC Exterior Beam-Column Subassemblages for Progressive Collapse. ACI Structural Journal, Vol. 108, No. 5: 542-552. 